\title{
The Professional Spine: Creation of a Four-year Engineering Design and Practice Sequence $^{1}$
}

\author{
Brian M. Frank, Ph.D., P.Eng. \\ Director (Program Development) \\ Queen's University \\ brian.frank@queensu.ca
}

\author{
David S. Strong, P.Eng. \\ NSERC Design Chair \\ Queen's University \\ strongd@ appsci.queensu.ca
}

\author{
Rick Sellens, Ph.D., P.Eng. \\ Assoc. Prof., Mech. Eng. \\ Queen's University \\ rick.sellens@queensu.ca
}

${ }^{1}$ This paper was also published in the ASEE 2011 Annual General Conference with joint permission of ASEE and CEEA.

\begin{abstract}
This paper discusses the development of a four-year Engineering Design and Practice Sequence (EDPS) of project-based courses at Queen's University. The four-year sequence is a core requirement for all engineering students, and will develop competence in design process methods and tools, problem analysis, creativity, economics and entrepreneurship, engineering communications, professionalism, and ethics. The EDPS was designed to meet requirements of the Canadian Engineering Accreditation Board graduate attributes, which addresses requirements of the Washington Accord. They also target applicable elements of the CDIO syllabus. The EDPS is being delivered to first year engineering students for the first time in the 2010-2011 academic year and will continue rolling out over the next three years.

The paper discusses the process involved in creating the sequence, the course objectives and delivery for each year of the program, and proposed assessment and evaluation methods. The sequence will also be compared to previously published engineering design and practice sequences. The outcomes of the first year, including student feedback and attribute assessment, will also be discussed. Upper year students who will not experience the engineering design and practice sequence are being assessed on their understanding of design methods to provide baseline data for comparison with students who progress through the sequence in future years.
\end{abstract}

\section{Introduction}

Increasingly engineering educators see value in establishing a connected sequence of experiences that focus on engineering design and practice in undergraduate engineering programs. Notable reports on the future of engineering education conclude that students should be provided an opportunity to integrate knowledge and skills in activities of increasing complexity that emulate engineering practice throughout their program [3], [20]. Experiences of this type exist in some programs but are relatively rare and often not published. Research at our institution and elsewhere has demonstrated a need for repeated involvement in design activity for students to build competence and confidence in engineering activities [7],[8],[9],[14].

This paper will discuss the development of a four-year Engineering Design and Practice Sequence (EDPS) of project-based courses at Queen's University, a midsized Canadian university. The course sequence was developed over the past two years by a committee consisting of faculty representatives from all engineering programs in the faculty of engineering, a student society representative, administrators, and invited experts.

\section{Pedagogical Basis for EDPS}

The curriculum design draws upon the cognitive apprenticeship framework from Collins, Brown, and Newman that builds upon the idea of an apprenticeship which "embeds the learning of skills and knowledge in their social and functional context."[2] The cognitive apprenticeship model maintains the importance of developing abstract and general skills commonly required in professional programs and proposes experiences designed to teach the processes used by experts to complete complex tasks by applying conceptual and factual knowledge in an appropriate context. In many ways this is the model used in graduate engineering education, whereby students develop mastery in their field by observing the processes used by an expert (a supervisor or designate), receiving coaching, and 
gradually becoming more independent in applying techniques, tools, and processes. This differs from the traditional approach to undergraduate education:

“...standard pedagogical practices render key aspects of expertise invisible to students. Too little attention is paid to the process that experts engage in to use or acquire knowledge in carrying out complex or realistic tasks... Few resources are devoted to higher order problem-solving activities that require students to actively integrate and appropriately apply sub-skills and conceptual knowledge." [2]

One of the key outcomes of a professional program is to help students begin the process of moving from novices to experts. Novices differ from experts not only by the amount of knowledge, but in how the knowledge is organized and utilized. This development includes helping students progress in their epistemological assumptions, described by King and Kitchener as being three primary phases: [13]

- Pre-reflective thinking: do not acknowledge or perceive that knowledge is uncertain. Do not understand that some real problems have no absolutely correct answer.

- Quasi-reflective thinking: recognize that some problems are ill structured and that some issues are problematic. Do not understand how evidence leads to conclusions - have difficulty drawing reasoned conclusions

- Reflective thinking - knowledge must be actively constructed and understood in relation to context in which it was generated. Conclusions must remain open to reevaluation.

Students often begin undergraduate programs struggling with the differences between closed-ended and open-ended problems, and using evidence to support conclusions. This approach will include modeling, coaching, and scaffolding [2] to help student begin the progression from novice to expert.

The intention is not to use this model exclusively in an undergraduate program, but rather as one experience among others that support factual and conceptual knowledge development and engineering skill (e.g. use of tools) occurring elsewhere in the engineering program.
Recent engineering reports have recommended curricular changes based on these approaches, including an adoption of a cognitive apprenticeship model by Sheppard et. al.[20] Specifically there have also been recommendations for the development of a professional spine of courses. From Sheppard, the first principle recommended for improving engineering education is:

"Provide a professional spine: During each year of their program, students should have experience with and reflect on the demands of professional practice, linking theory and practice. Engaging in increasingly practicelike experiences, the engineering equivalent of the clinical dimension of medical preparation would be a central feature of engineering education. This emphasis on professional practice would give coherence and efficacy to the primary task facing schools of engineering: enabling students to move from being passive viewers of engineering action to taking their place as active participants or creators within the field of engineering. In this process, the student would begin to develop an identity as an engineer.’[20]

CDIO Standards 3, 4, 5, 7, and 8 mandate the curriculum components key to EDPS and their integration.[3] Those standards are: Integrated Curriculum, Introduction to Engineering, Design Build Experiences, Integrated Learning Experiences, and Active Learning. The standards require at least two design/build experiences integrated into the core curriculum and encourage more.

CDIO Standard 1 - CDIO as Context states "Adoption of the principle that product and system lifecycle development and deployment - Conceiving, Designing, Implementing, and Operating - are the context for engineering education" (cdio.org) The standards document expands on this to state "[students] should be able to participate in engineering processes, contribute to the development of engineering products, and do so while working in engineering organizations. This is the essence of the engineering profession." This has been widely interpreted among the collaborating programs to require learning experiences that mimic engineering practice in addition to traditional knowledge base courses.

This is in contrast to the common "bookend approach" to engineering design which introduces a fairly non- 
technical design project in the first year, a comprehensive very technical capstone design project in fourth year, and little design experience in between. This approach has been demonstrated to lead to poor retention of design skill, and in fact regression in both confidence and ability to apply a design process.[7],[14] On a recent student survey after the last delivery of a first year design project module only $42 \%$ of respondents said they felt confident tackling complex problems, suggesting a need for additional focus.

Engineering employers have also pointed to a need to enhance development of professional skills. In an extensive 2007 survey that assessed the views of both engineering practitioners and engineering students on a broad set of engineering design and practice competencies, many differences were found between the expectations of the practitioners and the perceived abilities of the students [15]. Some of the most significant concerns were in oral and written communication, teamwork, and creativity. These elements and others discussed in the survey portray a significantly lower than expected capability in the expected skills of graduating engineering students.

In the same year, another survey commissioned by Engineers Canada and the Canadian Council of Technicians and Technologists produced similar results. "Employers expressed a high level of satisfaction with the science-based skills of new hires, but a lower level of satisfaction with non-technical skills."[4] In the 0-5 year category, $87 \%$ of employers were satisfied with science-based skills of new hires, while only $64 \%$ were satisfied with their "nontechnical skills". It is also interesting to note that in both surveys, communication skills and teamwork skills were ranked in the top 3 of the non-technical skills category, providing a very consistent message as to their importance in the workplace.

\section{Examples of Other Design Sequences}

There are a number of engineering schools in North America that offer design and/or professional skills sequences or "spines" within their programs. However, based on the information available in the literature, most of these spines are either within discipline-specific programs or within engineering schools that offer "general" engineering programs with some flexibility in choice of courses or course streams. As examples of discipline-specific sequences, the University of Sherbrooke introduced a four year design spine in their Mechanical Engineering program in 1994. The University of Manitoba created a "design trilogy" sequence in their Biosystems program in 2003 [15].

Harvey Mudd College offers a full design sequence within their unique engineering program that offers several options within a general engineering program. One of their three "core stems" focus is on Design and Professional practice, consisting of three introductory design courses (including experimental design) and then 3 engineering "clinic" courses in the final years [15].

Stevens Institute of Technology implemented a "Design Spine" a number of years ago. Stevens first year includes technical drawing, disassembly, teaming, and communications.. They have five semesters of general multidisciplinary design followed by three of discipline specific effort. Design experience is integrated with technical content (thermodynamics, materials, instrumentation, etc.), and a "theme" is suggested each semester to provide a link between engineering science courses and design [19].

The University of Guelph, which offers five engineering programs within their School of Engineering, has incorporated a design sequence since 1973. [15] Their first year introduces design process, constraints, project management and teamwork. Second year builds on these skills and begins to integrate the engineering sciences and adds additional elements including creativity concepts. The third year continues the progression of skills development and projects are drawn from industry, government and non-profits. The final year capstone design course allows students to pursue entrepreneurial projects of their own choosing or with external partners. In all years, students are free to work in multidisciplinary teams according to their own preferences [21]. Guelph is one of the only documented North American engineering schools with separate discipline-specific programs that offers fully multi-disciplinary design courses in all four years of their undergraduate program.

The remainder of the paper will examine the development of the EDPS at Queen's University.

\section{Related earlier development}

Historical roles were critical to laying the foundation for the collaborative development required to 
implement the EDPS. Strong support from the Dean in the 1990's led to the development of faculty roles to promote educational innovation, including a former Associate Dean (Integrated Learning), and Associate Dean (Program Development). These positions contributed to a broader Integrated Learning initiative that saw the design and construction of a novel Integrated Learning Centre, along with associated personnel, hiring of an NSERC Chair in Engineering Design, and creation of an endowed Chair in Engineering Education Research and Development [15],[16],[18]. This led to administrative support for faculty in seeking innovative approaches to education, and creating a supportive culture for new faculty. Innovative curriculum in the common first year was a direct result of this effort.[6],[22]

A second year design course in the Mechanical and Materials Engineering program, MECH 212, was developed and has been jointly offered by multiple faculty and evolved through delivery over more than 15 years. It addresses many of the objectives of the Professional Spine in a discipline specific way and many of its proven successful features are being included in the second year implementation of the Professional Spine.

In 2004, a new 2 year sequence of upper-year elective multidisciplinary design courses was introduced, one primarily introducing design tools and techniques in a PBL environment, the other an industry-funded full year team client-based multidisciplinary design project.[24] Although departmental support for the multi-disciplinary option was initially cautious, student demand and outstanding feedback from project partners and employers quickly encouraged most departments to approve the courses, including substitutions for departmental capstones in the final year Multidisciplinary Design Project course. Substantive interest in these courses from both students and external partners, along with survey results and changes in accreditation, reinforced the need to expand design and professional skills across all programs.

The experience an course successes informed the development of the EDPS.

\section{Curriculum development process for EDPS}

In the summer of 2009 the dean of engineering held a retreat to establish priorities in undergraduate curriculum development. Attendees included the dean, associate dean (academic), director (program development), chair in design engineering, department heads, and undergraduate chairs. Previous buy-in to the importance of continuing to innovate in engineering education, as discussed above, was critical to this process. A professional facilitator structured the retreat, which included a strengths, weaknesses, opportunities, and threats (SWOT) analysis, and a curriculum vision.

The top curriculum development priorities from this retreat were as follows:

- Integration \& reinforcement of core competencies in design and professional skills, societal issues, economic, policy etc. with related courses in all four years of the program

Integrative education: integration of technical/professional skills through all four years, without loss of core competency in the hard technical skills, recognizing that core competencies will differ across disciplines

O Strengthen integration of fundamentals in math and science in upper years of programs

- Curriculum will be designed on a facultywide basis. Coordination between departments across the entire faculty to improve efficiency in content delivery

- Emphasize balance: between teamwork and individual work; project based learning (PBL) and other methodologies

- More integration of ideas from different courses ( increase cooperation so students see connections between courses)

- Student centric: must keep student as the focus of all curriculum changes

○ Quality, as assessed by the National Survey of Student Engagement (NSSE), surveys, internal academic reviews, and other indicators will be maintained and enhanced

○ More opportunities for studentfaculty interaction 
As a result of this effort, the Dean's Retreat Curriculum Review Committee (DRCRC) was established to implement the key objectives. Membership included the Associate Dean (Academic), Director (Program Development), the NSERC Chair in Engineering Design, one faculty member representing each department, the undergraduate society's vicepresident (academic), and members with particular expertise including the economics coordinator, professionalism instructor, and engineering librarian. The first priority of the committee was implementing the first objective: creating a sequence of courses in engineering design and practice. The committee began meeting roughly once per month in the summer of 2009.

Faculty-wide adoption of "guiding principles" was critical to the implementation of the professional spine. This agreement in principle facilitated the progress of the committee, and ensured universal acceptance across the Faculty. All departments were invited to provide representation on the committee developing the new curriculum. One of the other key elements in this effort was the ability to reflect on and draw from other successful, and in some cases unique, courses that had been previously implemented, such as APSC-100 (Engineering Practice), APSC 190 (Professional Engineering Skills), MECH 212 (Design Techniques), and APSC-381 (Fundamentals of Design Engineering). These previous courses illustrated various ways and means of teaching and learning design and professional skills at both the faculty-wide and departmental levels.

It should also be noted that Faculty office has invested significantly in both financial and human resources to support engineering education development. In addition to the resources committed in the "early development" (above), financial and human resource commitment has continued to date. One example of this is a commitment by the current Dean to financially subsidize the departments in exchange for their commitment to provide departmental representatives to work on the curriculum development steering and subcommittees. This support provided faculty time to work on this initiative.

The process generally followed a curriculum design flow [23], beginning by establishing high-level objectives. These objectives included:
- Enhance design and innovation capacity required in both academic and industrial settings

- Project based, with appropriate scaffolding in early years to develop project management, design process, teaming, communications skills

- Include plans for graduate attribute assessment, required by the Canadian Engineering Accreditation Board (CEAB $)^{5}$

- Includes the majority of the CEAB accreditation units required in engineering design

- Ensure structure is designed to allow future multidisciplinary projects

- Encourage professional behaviour and skills

- Utilize peer mentorship to develop leadership and additional support for early year students

Following the guidelines of the Washington Accord [12], the CEAB has established a requirement for Canadian engineering programs to demonstrate that graduates possess attributes in twelve categories [5].

The EDPS is designed to provide a learning environment to support development of all attributes except knowledge base. That is not to say that the attributes are not developed outside the sequence, but rather that the EDPS serves to provide an opportunity to develop and assess these attributes in an integrated experience emulating professional practice.

Using this starting point, the group began by focusing on high-level learning objectives in each year, which will be discussed in a later section. These objectives were established over a 4 month period. The engineering program has a common first year after which students select one of ten disciplines beginning in their second year. Hence the EDPS has been designed to work within that structure.

The first year course in the sequence is a design and professional skills course that had existed for over a decade, APSC-100. The course consisted of a module on design of experimentation and data analysis, and one centered around a team- and client-based engineering design project. The committee determined this experience was an appropriate foundation for the EDPS, and the course was expanded to introduce a module focusing on complex problem solving and modeling. Details of objectives and implementation are discussed below. 
The committee then moved on to detailed design of the second year experience, using learning objectives established earlier. Several subcommittees were created to focus on design, communications, and professionalism in the second year. Ideas were brought back to the larger committee to discuss implementation options including: (a) whether the second year course should be faculty-wide or implemented separately in each department, and (b) whether communications should be delivered within the same course, or in a separate course delivered by the same instructors. By the summer of 2010 there was a general agreement on the nature of the second year experience. The committee felt that the most effective way to meet the overall EDPS objectives, while making efficient use of faculty time and expertise, was to implement a faculty-wide, one semester design course. The communications objectives were put into a separate course, coordinated by the same instructors as the design course, that provides appropriate instruction and feedback for communication deliverables in the design course. This decision was made primarily for administrative reasons, as it allows a way of tracking students separately on their competencies for both communications or design.

The course will be offered in the 2011-2012 academic year. The committee is also working to develop a complementary stream of leadership development courses on topics like peer mentoring. The committee will be developing a detailed plan for the third year experience over the spring and summer of 2011, and a plan for fourth year in the spring and summer of 2012.

\section{Student Learning Outcomes}

In addition to the larger objectives of the spine, the achievement of specific student learning outcomes is the primary goal of each of the individual components of the spine. Each outcome is phrased in terms of a verb indicative of a level of mastery and a subject phrase and reflects activities students will be able to do. Each outcome should be directly assessable from a single student deliverable or observation and may be assessed multiple times. For clarity, the outcomes for each year are presented in parallel with the descriptions of course implementation. Some outcomes have been combined or condensed for brevity and full detail is still being developed for the third and fourth year courses.

\section{Implementation and Detailed Outcomes}

The EDPS follows an escalating series of multiple sequences of modeling, coaching and scaffolding to allow students to succeed in progressively more complex design tasks. The first and second year courses focus on using basic engineering and physics knowledge while developing design and communication process skills common across engineering. The third year courses will apply advanced, discipline specific technical tools to generate reliable predictions of system performance to support the independent team projects that students will complete in fourth year. The implementation and outcomes are detailed year by year below.

First year (APSC-100): This course introduces fundamental professional engineering skills and provides an opportunity to apply engineering science and mathematics content in situations emulating professional practice. It consists of three modules: Module 1. Problem analysis and modeling; Module 2. Experimentation and measurement; Module 3: Engineering design. This course is running in 2010/2011 with the outcomes shown in Table 1 used for student evaluation.

The problem analysis and modeling module is an integrative experience that uses concepts from engineering sciences, natural sciences, and mathematics courses to solve complex open-ended problems. The course is structured around modeleliciting activities which are problems used in class that are set in a realistic context that requires the learner to document not only the solution to the process, but also their process for solving it. ${ }^{11}$ Problems include a failure analysis, decision making in an international development project, a feasibility study in alternative energy, and numerical modeling in a biomedical system. MATLAB is used as a computational tool to solve the problems. Students develop familiarity with the engineering profession by interviewing a practicing engineer and collaborating on recommendations for a new university teaching facility.

The experimentation and measurement module introduces experimental methods, data analysis, and error analysis supporting concepts in physics and chemistry. Students are required to design their own experiment to answer a question. This helps students develop the ability to setup and evaluate an investigation. 
The engineering design module centers around a teambased project where students are partnered with clients, primarily in the local community. Supporting activities focus on concepts including design process and tools, project management, information management, teaming, communication, personal learning styles, economics, and workplace safety. A key feature of this module is the use of upper year engineering students as project managers. These students serve as peer mentors, and are consistently highly regarded by first year students. Although they are hired to only manage these projects, in practice they also play the role of general academic peer mentors for first year students.

Approximately 50 upper year engineering students are hired in April for project manager positions in the next September-April academic year. Preference is given to those who have demonstrated leadership skills, industrial experience, academic strength, communication skills, and design skills. A significant number also have formal training in design tools and methodologies. At the beginning of the year all project managers are required to hold current workplace safety certification and first aid certification. They receive training over multiple sessions in course objectives, design process and tools, assessment and grading, conflict resolution, and general project management. Their role includes arranging initial meetings, giving feedback on team meetings, helping the teams create design plans, timelines and goals, providing guidance and feedback on oral presentations and written reports, guiding students to resources available at the university, and evaluation of team progress and deliverables.[6]

Second year (APSC 200/293): The two new second year courses are faculty wide, and will draw on expertise from across the faculty, but will be coordinated by one person. One course focuses primarily on design, and the second on written and oral communications. The projects in the design course will serve as the context for the reports and presentations used in the communications course. This will provide multiple revision cycles to help students develop an effective writing process. The design activities are also supported by materials from APSC 221: Economics and Business Practices in Engineering. These courses will be offered in this form for the first time in 2011/2012, using the outcomes in Table 1.

In this project based design course, students will participate constructively on teams to create solutions to open-ended problems, using standard design methods and tools. The course opens with a discipline specific project activity during a single session in the first week to engage the students in an active learning opportunity. Instruction is provided primarily in the first 6 weeks of the semester focusing on problem scoping, creativity and idea generation, decision making incorporating technical, economic, societal, and environmental factors, safety, engineering codes and regulations, and engineering ethics. In that first six weeks student groups complete a simple design/build project to provide a focus for tools they are learning. The final 6 weeks of the course centers around a more advanced design project delivered by each discipline. This course is integrated with the communications course, and coordinated by the same instructor. The communication course will include a small number of lectures, online modules, and working tutorials supporting deliverables in the design course. This ensures the communications expectations occur in an engineering context.

Third year (various program specific courses and APSC 381): In third year students will more closely engage in program specific technical processes using quantitative design tools to understand system performance. Design projects will be more closely defined to exercise and assess those skills. Awareness of the link between technical and professional skills will be emphasized in specific case studies to prepare students for more diverse design project activities in fourth year. Details of these courses have not been finalized, however they will include these common outcomes and elaboration for program specific needs:

- Applies appropriate technical knowledge, models/simulations, and computer aided design tools

- Creates and tests simulations, models, and/or prototypes at various points in design with complexity appropriate to design stage

- Quantifies performance, yield, reliability, and safety evaluations

- Applies basic economic tools in decision making

These discipline-specific courses will be offered in this form for the first time in 2012/2013. The current multidisciplinary third year design course, APSC 381, will continue to be available to students as an elective option. 


\section{Fourth year (program capstone design/communications courses and APSC 480):}

The capstone projects will all be team-based, solving complex, open ended problems for clients (ideally industrial partners), with students working semiautonomously under a faculty supervisor. All will produce written reports and design presentations at appropriate stages. Projects may be discipline specific under courses in each program, or multidisciplinary design projects in the Faculty-wide course APSC 480, "Multidisciplinary Design Project", available to students as a substitute for program specific capstone courses. Provisions are also in place to allow students to substitute capstone courses from other programs for their disciplinary capstone.

A set of 29 program independent outcomes, supporting 9 of the 12 CEAB Attributes, were applied on a pilot basis to the design and communications capstone in Mechanical and Materials Engineering (MECH 460/464) in Fall 2010. These outcomes will be revised and expanded to cover the full range of the Attributes 2-12 for application in the initial offering of these courses in 2013/2014.

\section{Planned assessment process}

The detailed learning outcomes will be assessed year by year as part of the grading process. The results will provide measures of student development both individually for grading and as a group to inform the process of continuous curriculum improvement. Outcomes detailed above are currently in use for direct student assessment in APSC 100 and current communications courses.

The outcomes from the full sequence of EDPS will be categorized by both CEAB Attributes and using the CDIO Syllabus for comparison. The relatively coarse CEAB comparison will demonstrate compliance with accreditation requirements. The far more detailed, but compatible, CDIO comparison will highlight areas of strength and weakness within our curriculum and our graduates.

The fourth year assessment process that will be used was modeled in the current capstone design course in mechanical engineering in Fall 2010 using these design documentation deliverables:
- Writing progress memos, leading meetings and preparing minutes

- Design Proposal written report with formal oral presentation

- Individual drafts of written work

- Final Design written report with poster presentation

The individual drafts and multiple presentation opportunities, combined with supervisor input and peer assessment provide adequate differentiation of individual performance within the team. The 29 final year outcomes were assessed within the appropriate deliverables by faculty supervisors or academic assistants, and the results agglomerated in a Moodle database. Grades were calculated directly from outcome assessments, resulting in a distribution similar to past offerings where simple numerical grades were used.

Student design skill assessments have been carried out at the beginning and end of several current design courses for three years.. Students are asked to select one of three scenarios which require a solution, and are asked to describe the process they would follow to design a solution to the problem. This year the assessment has expanded to some fourth year capstone courses. The performance of students in these courses will be used as a benchmark as student progress through the new engineering design and practice sequence.

\section{Outcomes to date}

In the 2010-2011 academic year the initial delivery of the EDPS has been in first year. Students were asked to complete a web-based survey in the new problem analysis and modeling module partway through the year. The response rate was approximately $30 \%$. Of those who responded, $56 \%$ felt that the model eliciting activities were helping them solve open ended problems and 59\% felt they were improving their understanding of the role of an engineer in society. Most students (62\%) also felt the skills in the course were important to develop. Concerns were raised over two issues in particular: the amount of time required to receive feedback on submitted assignments, and the workload. The workload and assignment instructions 
Table 1 - Outcomes for first two years of the EDPS

\section{EDP I Detailed Outcomes} (APSC-100)
EDP II Detailed Outcomes

(APSC-200, APSC-293)
- Identifies known and unknown information, uncertainties, and biases when presented a complex ill-structured problem

- Creates process for problem solving including justified approximations and assumptions

- Selects and applies appropriate quantitative model and analysis to solve problems

- Evaluates validity of results and model for error, uncertainty

- Generates ideas and working hypothesis

- Designs investigations involving information and data gathering, analysis, and/or experimentation

- Synthesizes data and information to reach conclusion

- Appraises the validity of conclusion relative to the degrees of error and limitations of theory and measurement

- Adapts general design process to design system, component, or process to solve open-ended complex problem.

- Accurately identifies significance and nature of a complex, open-ended problem

- Identifies customer and user needs

- Gathers and uses information from appropriate sources, including applicable standards, patents, regulations as appropriate.

- Produces a variety of potential design solutions suited to meet functional specifications

- Performs systematic evaluations of the degree to which several design concept options meet project criteria

- Compares the design solution against the problem objective

- Selects appropriate measurement devices or techniques to accomplish a task

- Follows protocols when using techniques, skills and tools

- Demonstrates correct use of testing apparatus, databases and models

- Recognizes a variety of working and learning preferences

- Assumes responsibility for own work and participates equitably

- Describes own temperament

- Applies principles of conflict management to resolve team issues

- Critically analyzes results from a temperament sorter, defending opinion of how well results apply

- Analyzes impact of own temperament on group work

- Exercises initiative and contributes to team goal-setting

- Writes using standard formats

- Writes using standard grammar and mechanics

- Summarizes and paraphrases written work accurately with appropriate citations

- Delivers clear and organized formal presentation following established guidelines

- Creates effective figures, tables, and drawings employing standard conventions to compliment text.

- Describes role of protection of the public and public interest in decision making

- Demonstrates punctuality, responsibility and appropriate communication etiquette

- Participates actively in meetings, helps to generate ideas
- Demonstrate enthusiasm for engineering and the discipline they have selected

- Apply design processes and tools for problem definition, idea generation and decision making

- Promote creative processes in open ended problem solving

- Apply engineering principles and theories from other disciplinary courses

- Solve an open-ended design problem (involving analysis and/or simulation and/or prototyping)

- Analyze triple bottom line (financial, environmental, and public interest) to support decision making

- Apply relevant engineering regulations/codes/standards in a professional manner

- Explain the role of professional/technical associations in engineering and discipline

- Apply teaming skills in a group project

- Identify all relevant factors and the dominant factors in the system

- Apply information search and identification, with proper citations

- Demonstrate a communications strategy that considers the needs and character of the audience

- Compose logical arguments based on supporting evidence

- Compose with the appropriate structure and relationship amongst ideas

- Prepare and deliver a presentation with appropriate language, style, timing and flow

- Demonstrate writing with correct spelling, punctuation and grammar

- Demonstrate conciseness, crispness, precision and clarity of language

- Use appropriate formatting for a memo and a short report 
are being adjusted to resolve those concerns. A webbased survey and small focus groups will be setup at the end of the course to assess student self-reported confidence and perceptions of development.

The first year design project has run for over a decade, and the delivery will generally stay similar to previous offerings. In the past five academic years, satisfaction with upper year project managers has consistently exceeded $80 \%$ [6]. In the last delivery (January 2010), $78 \%$ felt the design module helped their teaming skills, $61 \%$ felt it helped their problem-solving skills. Only $42 \%$ said they felt confident tackling complex problems. $76 \%$ felt the experience improved their skills in solving open-ended design problems.

A set of approximately 20 outcomes are being assessed and evaluated to compare student performance to course expectations. The DRCRC will be analyzing the results and applying them to the improvement of the program.

The second year and fourth year segments have similar features to some existing design courses that have operated successfully for 5 years or more, providing a solid base for expanding these successes Faculty-wide.

\section{Conclusions}

The EDPS is a novel approach to creating faculty wide consistency in engineering design and professional practice education. It provides opportunities for students to experience a combination of multidisciplinary and discipline-specific projects throughout all four years of their programs. Students will meet a common set of design and professional practice learning objectives across all four undergraduate years of all ten degree programs. A multidisciplinary learning environment will be common to to the first year course, half of the second year course, and as an elective offering in the third and fourth years. The sequence provides an opportunity for students to integrate technical, design, and professional concepts in projects emulating professional practice.

\section{Acknowledgements}

The work discussed in this paper was primarily a result of cross-faculty collaboration by the Dean's Retreat Curriculum Review Committee within the
Faculty of Engineering and Applied Science at Queen's University. The authors would like to acknowledge extensive contributions of the many members of this committee over the past two years. The authors of this paper take full responsibility for its content, including any errors or omissions.

Funding provided by the Natural Sciences and Engineering Council of Canada (NSERC) through the Chairs in Design Engineering Program, and from DuPont through the DuPont Chair in Engineering Education, is gratefully acknowledged.

This paper was also published in the ASEE 2011 Annual general conference with joint permission of the ASEE and CEEA.

\section{References}

1. Britton, R. Charron, F., Dickinson, T., Little, P., and Stiver, W., "Design Sequence Experience: A Panel Discussion", CDEN 2004 Annual Conference, Montreal, QC

2. Collins, A, Brown, J., and Newman, S., "Cognitive Apprenticeship: Teaching the Craft of Reading, Writing, and Mathematics", ch. 14 of Knowing, Learning, and Instruction. Essays in Honor of Robert Glaser, ed. L. Resnick, Laurence Erlbaum Associates, 1989

3. Crawley, E et al., Rethinking Engineering Education: The CDIO Approach, Springer, New York, 2007, www.cdio.org.

4. Engineering and Technology Labour Market Study, 2007 Engineering and Technology Employer Survey, Engineers Canada and Canadian Council of Technicians and Technologists, accessed online Jan 18, 2011 at: http://etlms.engineerscanada.ca/media/2007\%20E mployer\%20Survey\%20Report1.pdf

5. Engineers Canada / Ingénieurs Canada (2009), Canadian Engineering Accreditation Board: Accreditation Criteria and Procedures / Bureau canadien d'agrément des programmes de génie: Normes et procédures d'agrément, 2009, accessed online October 7, 2010 at

http://www.engineerscanada.ca/e/files/Accreditati on_Criteria_Procedures_2009.pdf

6. Frank, B., and Mason, J., "Impact of PeerManaged Project-Based Learning in First Year Engineering", ASEE 2008 General Conference, Pittsburgh, PA

7. Frank, B., and Strong, D., "Development of a Design Skills Assessment Tool", 2010 Canadian Engineering Education Association Conference, Kingston, ON, accessed online March 7, 2011 at: http://library.queensu.ca/ojs/index.php/PCEEA/arti cle/view/3165/310 
8. Frank, B. , Strong, D, and Boudreau, J., and Pap, A., "Design Skill Assessment From Pre-University to Third Year", CDEN/C2E2 2009, Hamilton, ON.

9. Frank, B., and Strong, D., "Survey-Based Assessment of Design Skill Development in Engineering Project Courses", CDEN/C2E2 2008, Halifax, NS

10. Frank, B., "Development of processes and criteria for CEAB graduate attribute assessment", CDEN/C2E2 2009, Hamilton, ON.

11. Hamilton, E., Besterfield-Sacre, M., Olds, B., Siewiorek, N., "MEAs In Engineering: A Focus On Model Building", ASEE 2010 Annual General Conference, Louiseville, KY

12. International Engineering Alliance (2009), Graduate Attributes and Professional Competencies Paper, Version 2 - 18 June 2009. Accessed online October 7, 2010 at http://www.washingtonaccord.org/IEA-Grad-AttrProf-Competencies-v2.pdf

13. King, P., and Kitchener, K,. Developing Reflective Judgment: Understanding and Promoting Intellectual Growth and Critical Thinking in Adolescents and Adults. San Francisco: JosseyBass Publishers, 1994

14. Kotys-Schwartz, D. et al. (2010), "First year and capstone design projects: Is the bookend curriculum approach effective for skill gain?", ASEE Annual Conference 2010.

15. McCowan, J., and Knapper, C., An Integrated and Comprehensive Approach to Engineering Curricula, Part One: Objectives and General Approach, Int. J. Eng. Ed, Vol. 18, No. 6, p. 633, 2002
16. McCowan, J., and Knapper, C., An Integrated and Comprehensive Approach to Engineering Curricula, Part Two: Techniques, Int. J. Eng. Ed, Vol. 18, No. 6, p. 638, 2002

17. May, E., and Strong, D., "Preparing our students for success in Industry: A Proposal for Change", CDEN 2007 Annual Conference, Winnipeg, MB

18. McCowan, J., An Integrated and Comprehensive Approach to Engineering Curricula, Part Three: Facilities, Int. J. Eng. Ed, Vol. 18, No. 6, p. 644, 2002

19. Sheppard, K. and Gallois, B., The Design Spine: Revision of the Engineering Curriculum to Include a Design Experience each Semester, American Society for Engineering Education Annual Conference Proceedings, Charlotte, North Carolina, June 1999, Session 3225

20. Sheppard, S. et al. (2008), "Educating Engineers: Designing for the Future of the Field", JosseyBass.

21. Stiver, W., "Sustainable Design in a second year engineering design course, I. J. Eng. Ed., vol 26, no 2., pp. 1-6, 2010

22. Topper, A., and Clapham, L., From Experiments to Experimentation; A New Philosophy for First Year Laboratories, C2E2 2001, Victoria

23. Wolf, P. and Christensen Hughes, J. (eds.) (2007), Curriculum Development in Higher Education: Faculty-Driven Processes \& Practices. New Directions for Teaching and Learning, Jossey-Bass Publishers. Available online at: http://www3.interscience.wiley.com/journal/11786 9107/issue

24. Strong, D., "Towards Effective Multidisciplinary Engineering Education: The Multidisciplinary Design Stream at Queen's University", CDEN 2005 Annual Conference, Kannanaskis, Alberta. 